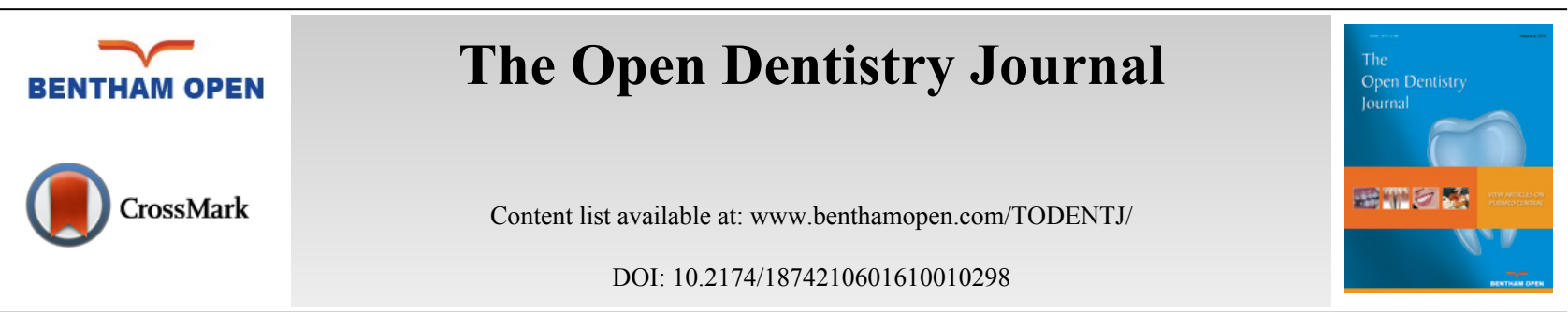

\title{
The Adjunctive Use of the Erbium, Chromium: Yttrium Scandium Gallium Garnet Laser in Closed Flap Periodontal Therapy. A Retrospective Cohort Study
}

\author{
Rana Al-Falaki ${ }^{*}{ }^{\ddagger}$, Mark Cronshaw ${ }^{\dagger}$ and Steven Parker ${ }^{\dagger}$ \\ ${ }^{\ddagger}$ Al-FaPerio Clinic, 48 A Queens Road Buckhurst Hill Essex IG9 5BY, UK \\ ${ }^{\dagger}$ Department of Surgical Sciences and Integrated Diagnostics, University of Genoa, Italy
}

Received: December 20, 2015

Revised: May 03, 2016

Accepted: May 09, 2016

\begin{abstract}
:
Objectives:

The current periodontal literature has been inconsistent in finding an added advantage to using lasers in periodontal therapy. The aim of this study was to compare treatment outcomes following root surface instrumentation alone (NL group), or with adjunctive use of Erbium, Chromium: Yttrium Scandium Gallium Garnet (Er,Cr:YSGG) laser (L group).

\section{Material and Methods:}

Patients diagnosed with generalized chronic periodontitis, having a minimum of 1 year follow up were selected by a blinded party for inclusion in a retrospective analysis from patients treated prior to and after integration of laser in a single clinic setting. Probing depths (PD) of all sites $\geq 5 \mathrm{~mm}$ and full mouth bleeding scores were analyzed. Further analysis was carried out on the treatment outcomes of only the molar teeth and of pockets $>6 \mathrm{~mm}$.
\end{abstract}

\section{Results:}

53 patients were included $(25 \mathrm{NL}, 28 \mathrm{~L})$. There was no significant difference between baseline PDs $(\mathrm{NL}=6.19 \mathrm{~mm}, \mathrm{~L}=6.27 \mathrm{~mm}$, range $5-11 \mathrm{~mm}$ ). The mean PD after one year was $2.83 \mathrm{~mm}(\mathrm{NL}) 2.45 \mathrm{~mm}(\mathrm{~L})$, with the mean PD reductions being $3.35 \mathrm{~mm}(\mathrm{NL})$ and $3.82 \mathrm{~mm}(\mathrm{~L})(p<0.002)$. The mean PD reduction for the molars were $3.32 \mathrm{~mm}(\mathrm{NL})$ and $3.86 \mathrm{~mm}(\mathrm{~L})(p<0.007)$, and for $\geq 7 \mathrm{~mm}$ group were $4.75 \mathrm{~mm}(\mathrm{NL})$ compared to $5.14 \mathrm{~mm}(\mathrm{~L})(p<0.009)$. There was significantly less bleeding on probing in the laser group after one year $(p<0.001)$

\section{Conclusion:}

Both treatment modalities were effective in treating chronic periodontitis, but the added use of laser may have advantages, particularly in molar tooth sites and deeper pockets. Further research with RCTs is needed to test this hypothesis further.

Keywords: Erbium Lasers, Furcation lesions, Laser -Periodontitis, Molar teeth, Non-surgical periodontal therapy, Periodontal Pockets.

\section{INTRODUCTION}

Chronic periodontal disease results from inflammation of the supporting structures of the teeth in response to chronic infections caused by various periodontopathic bacteria [1]. Bacterial biofilm plays a key role in the etiology of periodontitis [2]. Specifically, the challenge of periodontopathogens and their virulence factors may induce the release of pro-inflammatory cytokines, which elicit an inflammatory response and drive alveolar bone loss [3]. There is a

\footnotetext{
* Address correspondence to this author at the Al-FaPerio Clinic, 48A Queens Road Buckhurst Hill Essex IG9 5BY, UK; Tel: +44 208 5060701; E-
} mail: info@al-faperio.co.uk 
variation in host susceptibility and chronic periodontitis which may be considered as a genetically determined, inflammation-induced dysregulation of bone metabolism.

Periodontitis is the leading cause of adult tooth loss worldwide [4]. As an example, a recent nationwide survey found that periodontitis affects more than $50 \%$ of Americans above the age of 30 years [5]. Given its relatively high prevalence and the concerns at the potential systemic effects of living with a chronic infection, there is a recognition that technological advances and the development of new protocols may improve patient related outcomes and additionally address therapy cost effectiveness [6, 7].

The multiple species of periodontopathic bacteria present in periodontal disease co-exist and form symbiotic mutually supportive communities leading to pathogenesis [8]. Once formed the biofilm provides a mechanism for microorganisms to survive extreme temperature changes, radiation or mechanical trauma. Due to the structure and composition of the biofilm, the bacteria become very much more resistant to topical and systemic chemotherapy and biofilm formation is a highly successful and important microbial survival strategy [9].

One of the most active areas of research in periodontal therapy in the recent years has been the therapeutic use of lasers. To date, however the consensus views in the multiple systematic reviews and meta-analyses published over the past decade are that there is insufficient evidence to show a significant improvement in efficacy when compared with conventional scaling and root planing (SRP) alone [10 - 24]. Current advice is centered on root surface debridement with the option of surgical access in non-responsive disease sites.

The study reported here is a retrospective analysis of patients treated within a specialist periodontal practice comparing treatment with and without the adjunctive usage of an erbium, chromium: yttrium scandium gallium garnet $(\mathrm{Er}, \mathrm{Cr}$ :YSGG) laser $(\lambda 2780 \mathrm{~nm})$ in the management of pocket depths in both single and multi rooted teeth in the range of 6-11 mm pre-treatment, with up to one year follow up.

\section{AIM}

To compare treatment outcomes following root surface instrumentation alone (NL group), or with adjunctive use of Erbium, Chromium: Yttrium Scandium Gallium Garnet (Er,Cr:YSGG) laser (L group).

\section{MATERIALS AND METHOD}

The study was carried out to evaluate periodontal treatment modalities within a specialized private clinic setting. Statistically-sound conclusions drawn from the study would provide prospective strategy for future treatment protocols.

Patients with a diagnosis of generalized moderate to advanced chronic periodontitis, who had been treated with up to a minimum of one year follow-up were eligible for inclusion in the study. The non laser group consisted of patients treated with SRP prior to adoption of the laser in the specialist clinic and the laser group from other patients treated with the adjunctive use of the laser to SRP. These patients were selected in consecutive order based on if they met the criteria and were selected by a third party, other than the operator. Exclusion criteria consisted of any patients who had taken antibiotics any time between 3 months prior to initial consultation and the follow-up of one year and systemic diseases affecting immune response, such as poorly controlled diabetics.

53 patients were included in the analysis $(25 \mathrm{NL}, 28 \mathrm{~L}$ ). In the no-laser group, the age range was 38 to 72 (mean 55 years), while in the laser group the range was 40-72 (mean 55 years). There were 3 smokers in the no-laser group and 5 in the laser group. There were 1092 sites $\geq 5 \mathrm{~mm}$ in the no-laser group $v s .994$ sites $\geq 5 \mathrm{~mm}$ in the laser treated group. The mean PD at baseline for NL was 6.19mm (range 5-10mm), and for L 6.27mm (range 5-11mm). No statistical significance was found between the groups in the baseline data.

Patients were treated over two visits, with treatment on half the mouth (right or left) on each visit. Local anesthetic was administered, followed by supra and sub-gingival root surface debridement using ultrasonic scalers (Cavitron inserts SLI, SL-R and SL-L, Dentsply). For those patients receiving laser adjunct therapy, ultrasonic scaling was first carried out, followed by the use of the Er,Cr:YSGG laser (Biolase, Irvine, California) in each pocket. A radial firing periodontal tip of 500um diameter and $14 \mathrm{~mm}$ length (RFPT5) was used with settings of $1.5 \mathrm{~W}, 50 \%$ : $40 \%$ water: air ratio, $30 \mathrm{~Hz}$, fast pulse mode $(60 \mu \mathrm{s}, \mathrm{H}$ mode). The laser tip was inserted to the depth of the pocket parallel to the root surface and then moved in an apico-coronal and bucco-lingual direction to allow the laser energy to contact the entire root surface. In the case of root furcations, an attempt was made to insert the tip into each furcation area as far as possible. The tip was then directed away from the root surface towards the pocket lining and moved in a similar fashion 
to remove diseased pocket epithelium and diseased connective tissue. 30 seconds were spent in a pocket of $5 \mathrm{~mm}$, and 10 seconds were added for each $\mathrm{mm}$ as shown in Table $\mathbf{1}$. The tip was then used outside the pocket to disrupt outer epithelium to a surrounding distance of $5 \mathrm{~mm}$ from the pocket entrance. The disruption and superficial denaturation of the outer epithelium took approximately 10 seconds/tooth. This technique is essentially similar to the erbium yttrium aluminium garnet laser assisted periodontal therapy as described by Aoki et al. [22].

Table 1. Time spent in each pocket being treated with laser, dependent on pocket depth.

\begin{tabular}{|c|c|c|c|c|c|c|c|}
\hline Pocket Depth (mm) & 5 & 6 & 7 & 8 & 9 & 10 & 11 \\
\hline Time Spent in Pocket (s) & 30 & 40 & 50 & 60 & 70 & 80 & 90 \\
\hline
\end{tabular}

Patients were reassessed after 2 months, measuring probing depths (using a UNC 14mm probe, PDT, USA) and bleeding index. This was repeated at 6 and 12 months as part of a periodontal maintenance protocol. The same operator carried out all assessments and treatments.

Probing depths (PD) of all sites $\geq 5 \mathrm{~mm}$ and full mouth bleeding scores (BI) were analyzed for each group - laser (L) and non-laser (NL). Pocket depth reduction and number and percentage of residual sites $\geq 5 \mathrm{~mm}$ were calculated at each stage $(2,6,12$ months). In addition, two further subsets of each group were analyzed, consisting of all sites $\geq 7 \mathrm{~mm}$ and all molar teeth.

Statistical analysis was carried out on all the data using a variety of statistical tests (Independent Samples t-test, Paired t-test, and Chi-Squared) using SPSS software.

\section{RESULTS}

The mean PD at baseline for NL was $6.19 \mathrm{~mm}$ (range 5-10mm), and for L $6.27 \mathrm{~mm}$ (range 5-11mm). No statistical significance was found between the groups in the baseline data. The mean probing depths at one year were $2.83 \mathrm{~mm}$ (nolaser) and $2.45 \mathrm{~mm}$ (laser). The mean probing depth reductions for each group are shown in Fig. (1).

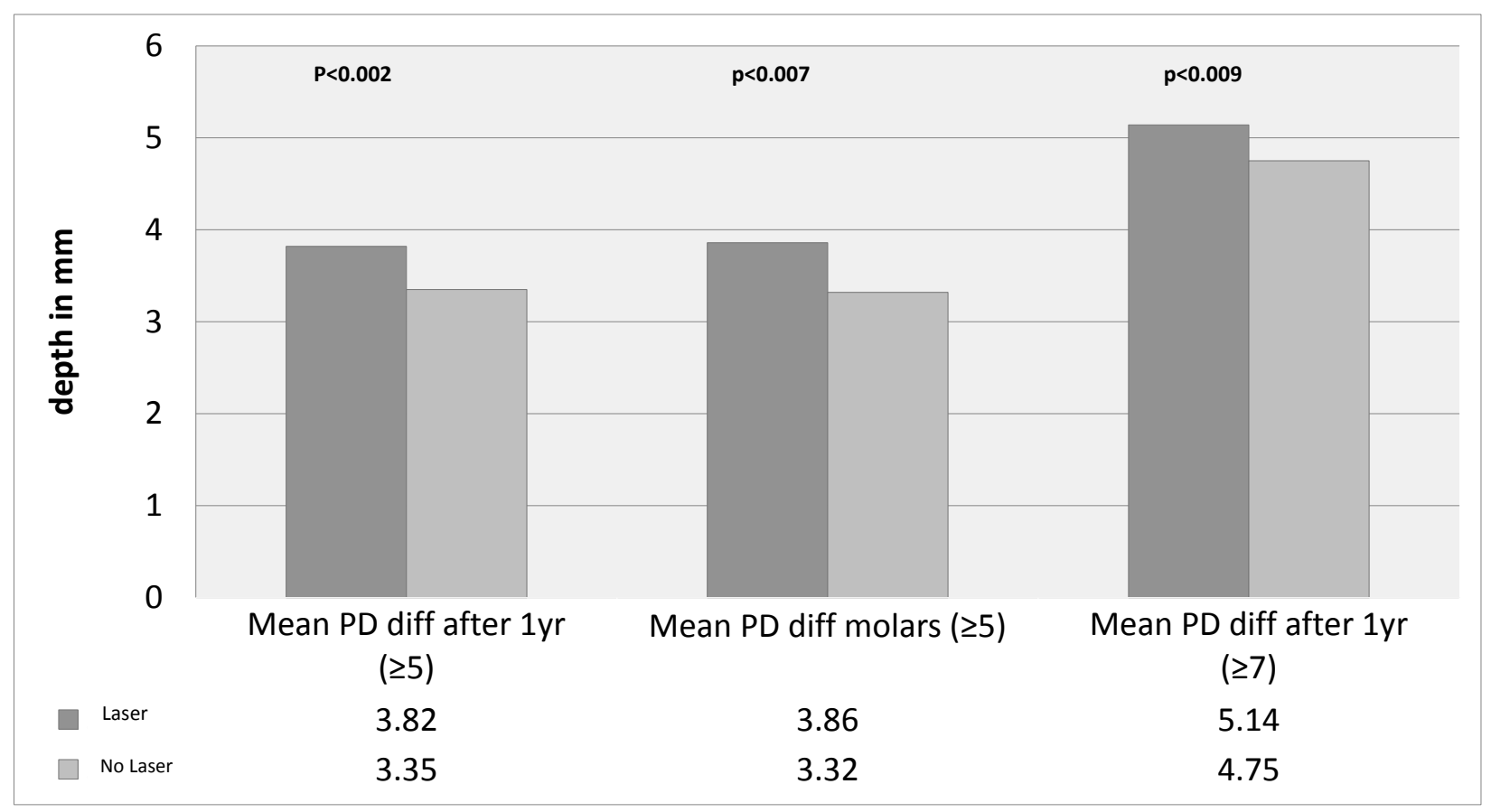

Fig. (1). Mean probing depth reduction ( $\mathrm{mm}$ ) after one year for the whole group (initial PD $\geq 5 \mathrm{~mm}$ ), subset of molars (initial PD $\geq 5 \mathrm{~mm}$ ), and subset all teeth (initial $\mathrm{PD} \geq 7 \mathrm{~mm}$ ).

There was no significant difference between the baseline bleeding scores, and both groups showed a significant reduction in bleeding index after 2 months $(p<0.001)$, but the Laser group had a significantly less bleeding on probing after 1 year $(p<0.001)$, as shown in Fig. (5). 


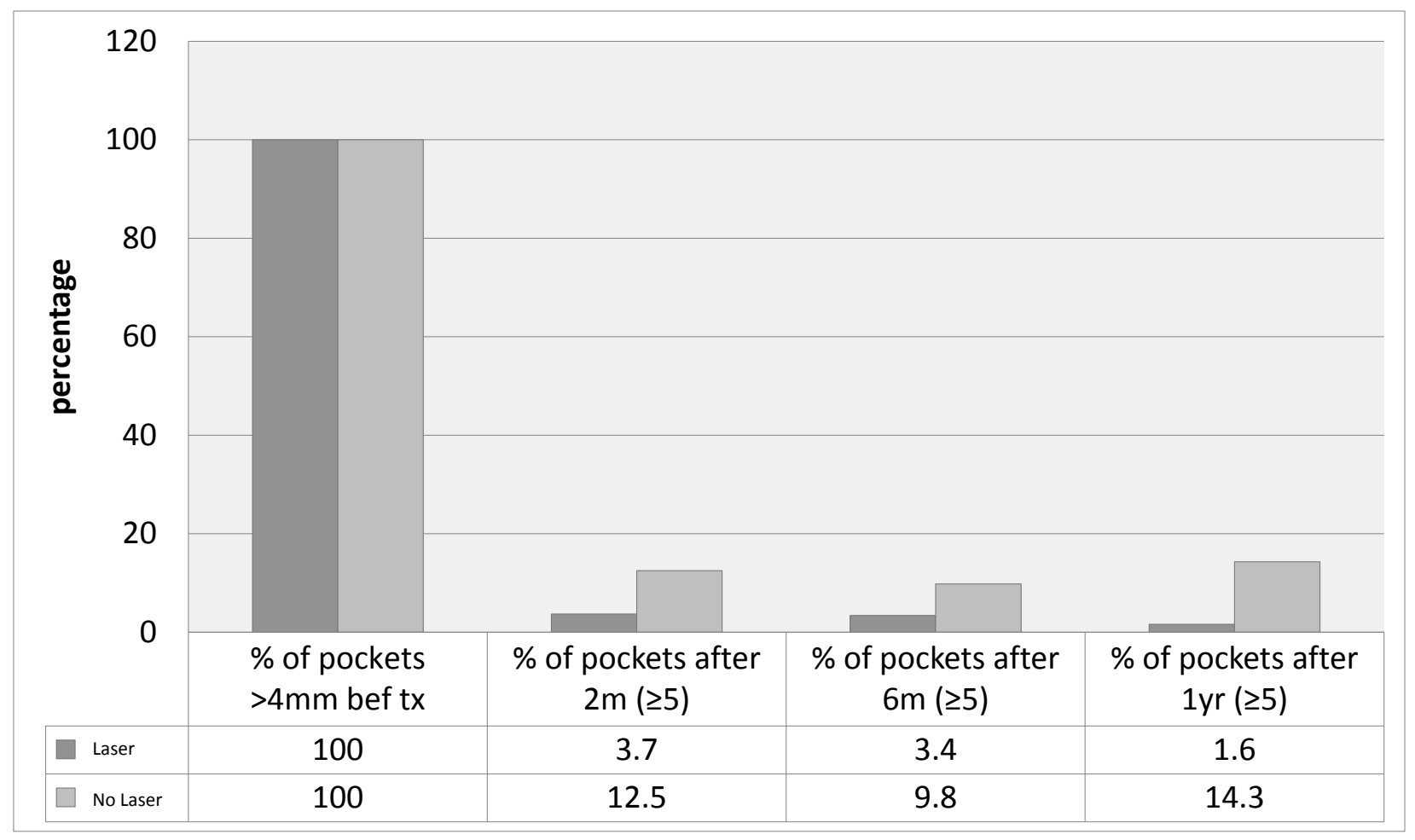

Fig. (2). Percentage of pockets remaining after 2 months, 6 months and one year for all laser and no-laser treated sites.

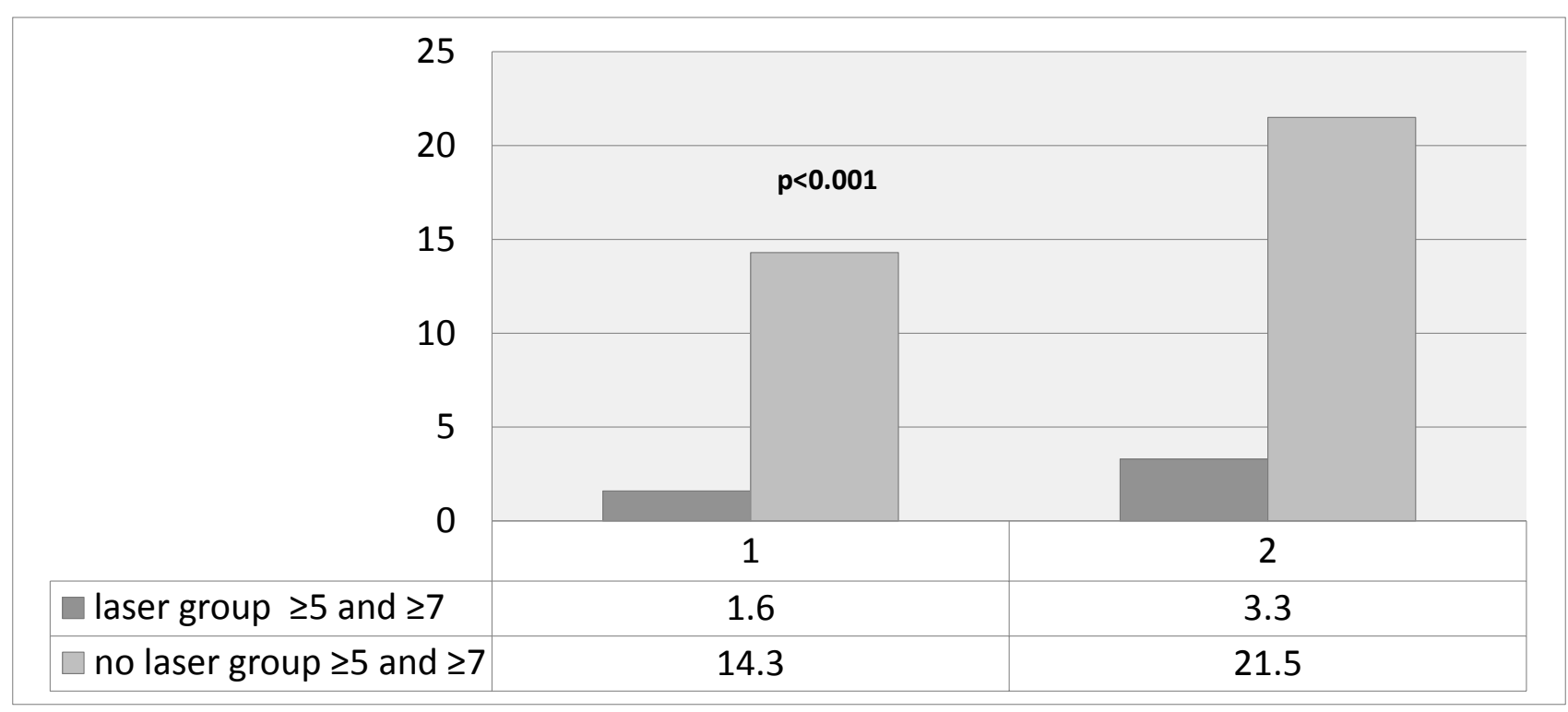

Fig. (3). Percentage of sites $\geq 5 \mathrm{~mm}$ remaining after one year in the whole group (1) and a sub-group of patients initial pockets $\geq 7 \mathrm{~mm}$ (2). Percentage of sites $\geq 5 \mathrm{~mm}$ remaining after one year laser or no-laser. 


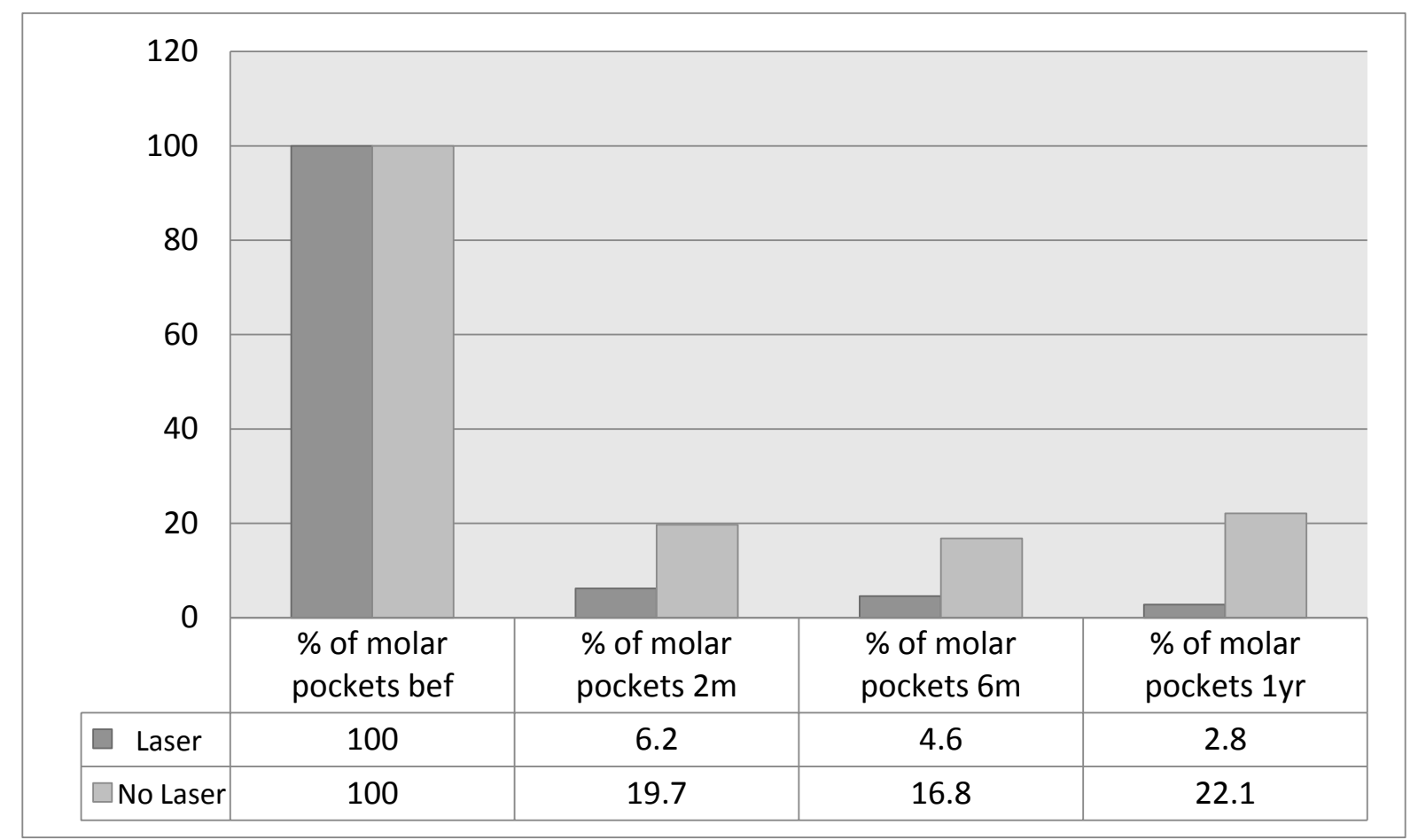

Fig. (4). Percentage of sites $\geq 5 \mathrm{~mm}$ remaining around molar teeth after 2 months, 6 months and one year, in laser and non-laser treated groups.

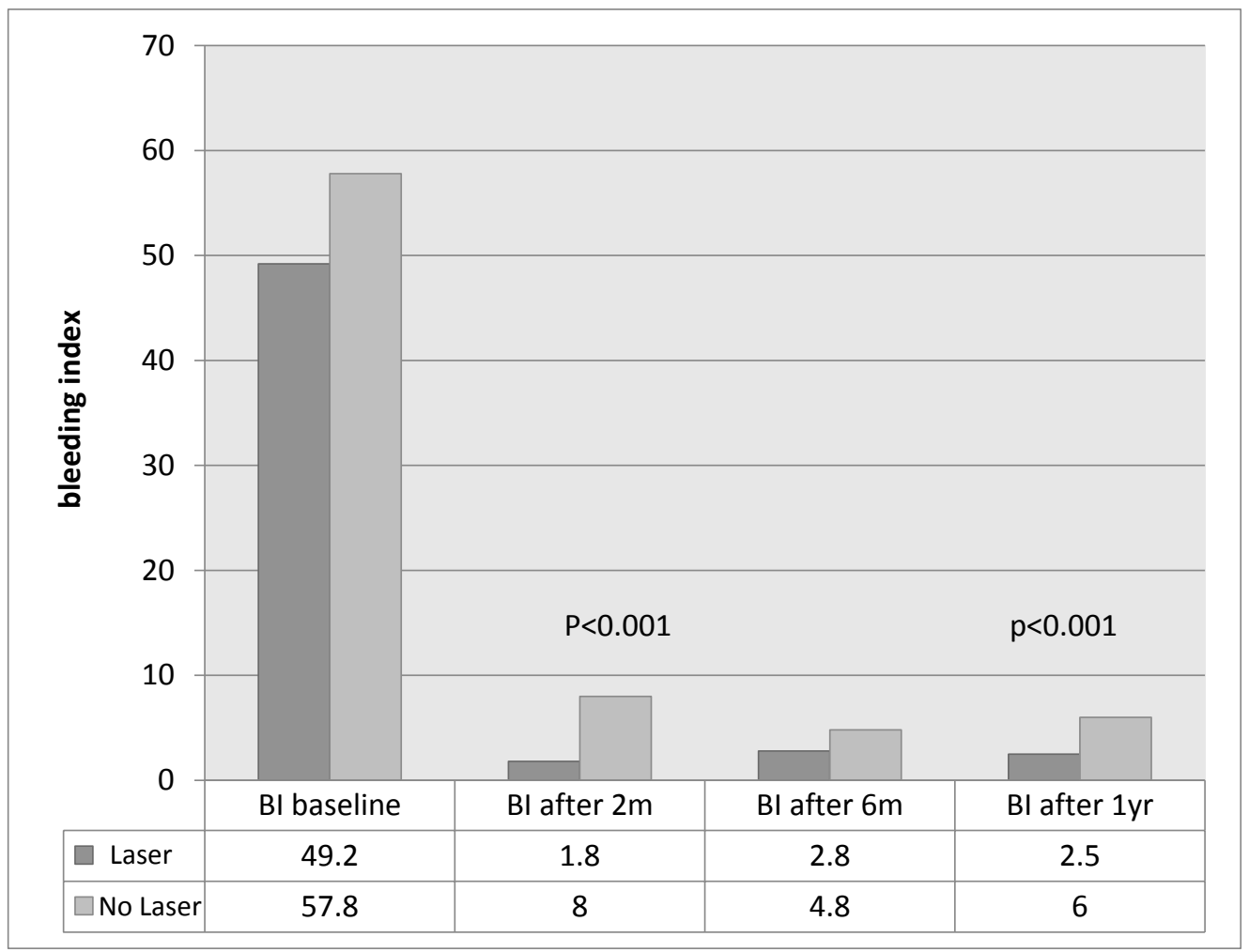

Fig. (5). Bleeding Index (\%)in each group after 2 months, 6 months and one year. 
There was a consistent trend in the pattern of stability demonstrated in the whole group as well as the subsets. After two months, there was a significant reduction in probing depths, number of pockets $\geq 5 \mathrm{~mm}$, and also percentage bleeding on probing. However, longer term follow up demonstrated a greater tendency for relapse in the group not treated with laser at the outset (NL), which seemed to start after 6 months and this was seen in all parameters and subgroups as shown in Table 2 and Figs. (1-5).

Table 2. Number and percentage of pockets at baseline and after one year in laser and no-laser treated groups for the whole group ( $\geq 5 \mathrm{~mm})$ and subsets of molars and deep pockets $\geq 7 \mathrm{~mm}$.

\begin{tabular}{|c|c|c|}
\hline Whole group & Laser Group & No Laser Group \\
\hline No. of sites $\geq 5 \mathrm{~mm}$ at baseline & 924 & 1092 \\
\hline No. of sites $\geq 5 \mathrm{~mm}$ after 1 year & 15 & 157 \\
\hline \% of sites $\geq 5 \mathrm{~mm}$ after 1 year & 1.6 & 14.3 \\
\hline Molar Subset & & 537 \\
\hline No. of sites $\geq 5 \mathrm{~mm}$ at baseline & 503 & 119 \\
\hline No. of sites $\geq 5 \mathrm{~mm}$ after 1 year & 14 & 22.1 \\
\hline \% of sites $\geq 5 \mathrm{~mm}$ after 1 year & 2.8 & \\
\hline No. of sites at baseline & & 347 \\
\hline No of sites $\geq 5 \mathrm{~mm}$ after 1 year & 334 & 75 \\
\hline$\%$ of sites $\geq 5 \mathrm{~mm}$ after 1 year & 11 & 21.5 \\
\hline
\end{tabular}

\section{DISCUSSION}

In the study presented here, there was a consistent trend in the pattern of response and stability demonstrated in the whole group, as well as the subsets. After two months there were significant reductions in probing depths, number of pockets $\geq 5 \mathrm{~mm}$ and also percentage bleeding on probing in both groups of patients. The greater probing depth reduction seen in the laser-treated group (and all the subsets of molars and $\geq 7 \mathrm{~mm}$ ) of $0.4-0.5 \mathrm{~mm}$ greater reduction was highly statistically significant, but one would perhaps question the clinical significance. However, longer term follow up demonstrates a greater tendency for relapse in the group not treated with laser at the outset, which seems to start after 6 months and this is seen in all parameters and sub-groups. These results are consistent with those reported by Kelbauskienne [25, 26] and Dyer \& Sung [27].

There have been numerous studies reporting on the efficacy or otherwise of the application of the Erbium family of lasers (Er:YAG $\lambda 2$ 2940nm \& Er,Cr:YSGG $\lambda 2780 \mathrm{~nm}$ ) in the management of chronic periodontitis. Some of these studies have looked at the use of the Erbium laser as an alternative to standard SRP and others have investigated combination therapies of SRP with the Erbium laser. There are conflicts and disagreements between the studies as there are some that report no clinical benefits compared to SRP alone, and on the other hand, there are studies that appear to show significant improvements in Erbium plus SRP treated patients. Kelbauskienne [25, 26], for instance, reports significant reductions of the indices measured of PPD \& CAL plus significantly reduced bleeding on probing compared to groups treated with SRP alone at 12 months. The clinical approach adopted involved debridement of the pocket by ultrasonic and hand instrumentation along with removal of the inner epithelium and surface denaturation of the outer epithelium using laser. In addition, diseased connective tissue was removed and the root surfaces subject to modification by application of the Erbium laser (Er,Cr:YSGG). This treatment approach is essentially similar to that described by Aoki $[22,28]$ and is not a non-surgical approach and ought to be considered as minimally invasive flapless surgery. Dyer \& Sung [27] described an excellent treatment outcome following minimally invasive surgery to treat persistent pockets using the Er,Cr:YSGG following SRP. Initial pocket depths of 7-9mm in the treatment group and CAL levels of $7.6 \mathrm{~mm}+/-0.6 \mathrm{~mm}$ improved to an average of $3.7 \mathrm{~mm}+/-1.2 \mathrm{~mm} \& 3.6+/-1.2 \mathrm{~mm}$, respectively. This significant clinical improvement was found to be maintained for a period of at least two years post-treatment. Dederich [29] presented a case report showing apparent bone infill into an intra-osseous defect following a minimally invasive approach adopting the Er,Cr:YSGG as an adjunct to pocket debridement and root surface preparation.

Gutknecht et al. [30] reported a case series of 12 patients with initial pocket depths in the range 2-8mm in a split mouth type study design. Following repeat laser applications using a radial firing 500 micron tip and the Er,Cr:YSGG it was found that at six months there was only a very small difference in pocket depth reduction between quadrants treated adjunctively with the laser and those treated solely by scaling and root planing. There was however a highly significant reduction in the periodontal pathogen counts favoring the laser treated pockets at three and six months compared to the 
control quadrants. This study concluded that this may lead to better long-term healing and stability compared to SRP alone.

Lasers generically have many intrinsic interesting and useful properties. For instance, there is the potential for producing different results depending on dose [31]. Laser tissue interaction can range in product from biochemical and biophysical promotion of healing and the selective suppression of the inflammatory cytokine cascade through to surgical ablation of diseased tissues and the photo-thermal destruction of pathogens [32 - 37]. There are major differences in laser target interaction and depth of tissue penetration between the various wavelengths of laser. However, all lasers have the potential to positively influence healing, repair and also the regeneration of tissues.

In vitro studies have demonstrated that the Er,Cr:YSGG laser can assist in calculus removal without thermal damage $[38,39]$. Also, it can be useful in the removal of smear layer. This in turn may be beneficial in enabling cell attachment in the regeneration of new attachment [40 - 43].

The potential benefits to be gained by the application of an Erbium laser in root surface bio-modification has been the subject of a recent review by Lavu et al. [44]. This interesting review states that the Erbium laser can be used safely for root surface modification, a proven anti-bacterial action, predictable calculus removal, and minimal root surface damage. Finally, that lased root surfaces appear to favor attachment of fibroblasts and blood components. The conclusion of this review is that Erbium lasers are a useful tool in the periodontists' armamentarium. To date, however the superiority of Erbium lasers over conventional treatment has not yet been clearly demonstrated.

Issues related to the prognosis post SRP have been analyzed by Cobb [45] in a review on non-surgical pocket therapy. Only a few sites within a small percentage of patients (8-12\%) do not respond to routine treatment. The majority of teeth (19-57\%) lost over a 15 year period are those initially diagnosed with furcation lesions compared to just $5-10 \%$ of those without furcation involvement.

The acknowledged evidence based approach to the management of chronic periodontal disease is pocket debridement by means of scaling and root planing. In deeper pockets $(\geq 7 \mathrm{~mm})$ the likelihood of a surgical approach is increased due to difficulties of access to deeper areas to ensure adequate debridement, particularly in multi rooted teeth [46].

In the present study it was found that 75/347 (21.5\%) of sites treated with scaling alone with initial pockets $\geq 7 \mathrm{~mm}$ had pockets $\geq 5 \mathrm{~mm}$ at one year. By contrast in the laser group at 1 year only 11/334 (3.3\%) of sites had pockets $\geq 5 \mathrm{~mm}$. Also, at one year bleeding indices were significantly lower in the laser group (2.5\%) compared to the non-laser group $(6 \%)$.

Gupta et al. [47] compared open flap reduction (OFD) to a minimally invasive approach using the Er,Cr:YSGG. Gupta et al. concluded that the two approaches resulted in similar gains in CAL. Of particular note was that there was a significant reduction in gingival recession in the laser group compared to the open flap debridement group at six months (0.6mm laser vs. $1.87 \mathrm{~mm}$ OFD). The PPD differed in favor of open flap debridement by around $1 \mathrm{~mm}$ at six months $(4.47 \pm 0.92$ laser $v s .3 .33 \pm 0.62$ OFD). In addition, there was a small but statistically significant outcome in relation to the reduction in gingival index at six months in favor of open flap debridement (0.52 laser vs. 0.95 OFD). Also, the reduction in the sulcular bleeding index at six months was again in favor of open flap debridement (0.53 laser $v s .0 .85$ OFD).

The parameters and clinical technique adopted by Gupta et al. are different in some regards to the approach described in this paper, which may have influenced the measured treatment outcome. Gupta et al. conclude that laser assisted pocket therapy offers a number of benefits including less mechanical trauma, less post-operative complications (swelling and pain), no need for antibiotics and analgesics post-operatively, a minimally invasive procedure with greater patient compliance and less time consuming with minimal bleeding. The clinical consequence in the study presented here of the consistently observed pocket reduction with apparent stability at 12 months and beyond has been to greatly reduce the need for open flap surgery. The less traumatic minimally invasive surgical approach is in accordance with the current trend within the non laser specialist periodontal community [48, 49].

In respect of the literature on lasers and PD therapy, there are conflicting opinions and confusion concerning the interpretation of treatment outcomes and their relevance to clinical practice. Also there are issues related to study design and the selection criteria for inclusion into meta-analyses and systematic reviews. 


\section{CONCLUSION}

The challenge of treating chronic periodontitis is to balance local and systemic etiologies, rationalize the available therapy options and address the complex architecture that may present as infra-bony pocketing.

The outcome of the study presented here must be viewed with caution as the measured clinical parameters were not blinded and this is not a controlled case study but rather a retrospective analysis and audit of patient data within a single clinic setting. The results are however sustained at a year and in view of the positive outcome of this study and the current evidence base, there is value in continued efforts to further evolve current attempts to integrate Erbium laser therapies as an adjunct to more conventional scaling and root planing periodontal treatment.

Both treatment modalities were effective in treating chronic periodontitis, but the added use of laser may have advantages, particularly in deeper pockets and molar teeth. Further research with RCTs are needed to test this hypothesis further.

\section{CONFLICT OF INTEREST}

The authors confirm that this article content has no conflicts of interests.

\section{ACKNOWLEDGEMENTS}

Dr. Rana Al-Falaki receives lecturing fees and occasional discounted equipment from Biolase, Statistical analysis was carried out by Dr Swatee Patel; head of biomedical statistics; University of Greenwich, UK.

\section{REFERENCES}

[1] Darveau RP, Tanner A, Page RC. The microbial challenge in periodontitis. Periodontol 2000 1997; $14: 12-32$. [http://dx.doi.org/10.1111/j.1600-0757.1997.tb00190.x] [PMID: 9567964]

[2] Socransky SS, Haffajee AD. Periodontal microbial ecology. Periodontol 2000 2005; 38: 135-87. [http://dx.doi.org/10.1111/j.1600-0757.2005.00107.x] [PMID: 15853940]

[3] Preshaw PM, Taylor JJ. How has research into cytokine interactions and their role in driving immune responses impacted our understanding of periodontitis? J Clin Periodontol 2011; 38(Suppl. 11): 60-84.

[http://dx.doi.org/10.1111/j.1600-051X.2010.01671.x] [PMID: 21323705]

[4] Axelsson P. Diagnosis and Risk Prediction of Periodontal Diseases. Quintessence Pub Inc. 2002. ISBN: 0-86715-363-6 237-51.

[5] Eke PI, Dye BA, Wei L, Thornton-Evans GO, Genco RJ. Prevalence of periodontitis in adults in the United States: 2009 and 2010 . J Dent Res 2012; 91(10): 914-20. [http://dx.doi.org/10.1177/0022034512457373] [PMID: 22935673]

[6] Axelsson P Minimally Invasive Treatment. Arrest and Control of Periodontal Disease Quintessence Pub. Inc. 2009; p. 85. ISBN: 978-086715-365-1

[7] Sanz I, Alonso B, Carasol M, Herrera D, Sanz M. Nonsurgical treatment of periodontitis. J Evid Based Dent Pract 2012; $12(3)($ Suppl.): 76-86. [http://dx.doi.org/10.1016/S1532-3382(12)70019-2] [PMID: 23040340]

[8] Hall-Stoodley L, Stoodley P. Evolving concepts in biofilm infections. Cell Microbiol 2009; 11(7): $1034-43$. [http://dx.doi.org/10.1111/j.1462-5822.2009.01323.x] [PMID: 19374653]

[9] Kuramitsu HK, He X, Lux R, Anderson MH, Shi W. Interspecies interactions within oral microbial communities. Microbiol Mol Biol Rev 2007; 71(4): 653-70.

[http://dx.doi.org/10.1128/MMBR.00024-07] [PMID: 18063722]

[10] Karlsson M, Lofgren C, et al. The effect of laser therapy as an adjunct to non-surgical periodontal therapy: A systematic review. J Periodontol 2008; 79: 2021-8.

[http://dx.doi.org/10.1902/jop.2008.080197] [PMID: 18980508]

[11] Sgolastra F, Petrucci A, Gatto R, Monaco A. Efficacy of Er:YAG laser in the treatment of chronic periodontitis: systematic review and metaanalysis. Lasers Med Sci 2012; 27(3): 661-73.

[http://dx.doi.org/10.1007/s10103-011-0928-8] [PMID: 21553003]

[12] Sgolastra F, Petrucci A, Severino M, Graziani F, Gatto R, Monaco A. Adjunctive photodynamic therapy to non-surgical treatment of chronic periodontitis: a systematic review and meta-analysis. J Clin Periodontol 2013; 40(5): 514-26. [http://dx.doi.org/10.1111/jcpe.12094] [PMID: 23557433]

[13] Sgolastra F, Severino M, Gatto R, Monaco A. Effectiveness of diode laser as adjunctive therapy to scaling root planning in the treatment of chronic periodontitis: a meta-analysis. Lasers Med Sci 2013; 28(5): 1393-402. [http://dx.doi.org/10.1007/s10103-012-1181-5] [PMID: 22895576]

[14] Sgolastra F, Severino M, Petrucci A, Gatto R, Monaco A. Nd:YAG laser as an adjunctive treatment to nonsurgical periodontal therapy: a meta-analysis. Lasers Med Sci 2014; 29(3): 887-95. 
[http://dx.doi.org/10.1007/s10103-013-1293-6] [PMID: 23474742]

[15] Slot DE, Jorritsma KH, Cobb CM, Van der Weijden FA. The effect of the thermal diode laser (wavelength 808-980 nm) in non-surgical periodontal therapy: a systematic review and meta-analysis. J Clin Periodontol 2014; 41(7): 681-92. [http://dx.doi.org/10.1111/jcpe.12233] [PMID: 24460795]

[16] Aoki A, Sasaki KM, Watanabe H, Ishikawa I. Lasers in nonsurgical periodontal therapy. Periodontol 2000 2004; 36: 59-97. [http://dx.doi.org/10.1111/j.1600-0757.2004.03679.x] [PMID: 15330944]

[17] American Academy of Periodontology Statement. American Academy of Periodontology statement on the efficacy of lasers in the nonsurgical treatment of inflammatory periodontal disease. J Periodontol 2011; 82(4): 513-4. [http://dx.doi.org/10.1902/jop.2011.114001] [PMID: 21453136]

[18] Cobb CM. Lasers in periodontics: a review of the literature. J Periodontol 2006; 77(4): 545-64. [http://dx.doi.org/10.1902/jop.2006.050417] [PMID: 16584335]

[19] Cobb CM, Low SB, Coluzzi DJ. Lasers and the treatment of chronic periodontitis. Dent Clin North Am 2010; 54(1): 35-53. [http://dx.doi.org/10.1016/j.cden.2009.08.007] [PMID: 20103471]

[20] Roncati M, Gariffo A. Systematic review of the adjunctive use of diode and Nd:YAG lasers for nonsurgical periodontal instrumentation. Photomed Laser Surg 2014; 32(4): 186-97.

[http://dx.doi.org/10.1089/pho.2013.3695] [PMID: 24697584]

[21] Ishikawa I, Aoki A, Takasaki AA, Mizutani K, Sasaki KM, Izumi Y. Application of lasers in periodontics: true innovation or myth? Periodontol 2000 2009; 50: 90-126. [http://dx.doi.org/10.1111/j.1600-0757.2008.00283.x] [PMID: 19388956]

[22] Aoki A, Mizutani K, Schwarz F, et al. Periodontal and peri-implant wound healing following laser therapy. Periodontol 2000 2015; 68(1): 217-69. [http://dx.doi.org/10.1111/prd.12080] [PMID: 25867988]

[23] Smiley CJ, Tracy SL, Abt E, et al. Systematic review and meta-analysis on the nonsurgical treatment of chronic periodontitis by means of scaling and root planing with or without adjuncts. J Am Dent Assoc 2015; 146(7): 508-24.e5. [http://dx.doi.org/10.1016/j.adaj.2015.01.028] [PMID: 26113099]

[24] Mizutani K, Aoki A, Coluzzi D. Lasers in minimally invasive periodontal and peri-implant therapy. Peridontol 2000 2016; 71: 185-212.

[25] Kelbauskienne S. A Evaluation of Er,Cr:YSGG Laser Application in Addition to Scaling and Root Planing in Patients with Early-Moderate Periodontitis. In: Doctoral dissertation. Lithuanian University of Health Sciences Medical Academy 2011.

[26] Kelbauskiene S, Baseviciene N, Goharkhay K, Moritz A, Machiulskiene V. One-year clinical results of Er,Cr:YSGG laser application in addition to scaling and root planing in patients with early to moderate periodontitis. Lasers Med Sci 2011; 26(4): 445-52. [http://dx.doi.org/10.1007/s10103-010-0799-4] [PMID: 20549280]

[27] Dyer B, Sung EC. Minimally invasive periodontal treatment using the Er,Cr: YSGG laser. A 2-year retrospective preliminary clinical study. Open Dent J 2012; 6: 74-8.

[http://dx.doi.org/10.2174/1874210601206010074] [PMID: 22615717]

[28] Aoki A. Current status of Er:YAG laser in Periodontics; World Federation of Laser Dentistry. 2010; Dubai Congress, 9-11 March, 2010. Conference Booklet.

[29] Perio DN. Periodontal bone regeneration and the Er,Cr:YSGG laser: A case report. Open Dent J 2013; 7: 16-9. [http://dx.doi.org/10.2174/1874210601307010016] [PMID: 23524914]

[30] Gutknecht N, Van Betteray C, Ozturan S, et al. Laser supported reduction of specific microorganisms in the periodontal pocket with the aid of the ErCr:YSGG laser. A pilot study. ScientificWorldJ 2014; 1: 1-7.

[31] Parker S. Laser:Tissue interaction and its application in clinical dentistry. Int J Laser Dent 2011; 1: 1-8. [http://dx.doi.org/10.5005/jp-journals-10022-1001]

[32] Carroll JD, Milward MR, Cooper PR, Hadis M, Palin WM. Developments in low level light therapy (LLLT) for dentistry. Dent Mater 2014; 30(5): 465-75. [http://dx.doi.org/10.1016/j.dental.2014.02.006] [PMID: 24656472]

[33] Tuner J, Hode L. The Laser Therapy Handbook. Prima Books 2007. ISBN: 91-631-1345-7

[34] Kesler G, Shvero DK, Tov YS, Romanos G. Platelet derived growth factor secretion and bone healing after Er:YAG laser bone irradiation. J Oral Implantol 2011; 37(Spec No): 195-204. [http://dx.doi.org/10.1563/AAID-JOI-D-09-00120.1] [PMID: 20594059]

[35] Pourzarandian A, Watanabe H, Ruwanpura SM, Aoki A, Ishikawa I. Effect of low-level Er:YAG laser irradiation on cultured human gingival fibroblasts. J Periodontol 2005; 76(2): 187-93. [http://dx.doi.org/10.1902/jop.2005.76.2.187] [PMID: 15974841]

[36] Pourzarandian A, Watanabe H, Ruwanpura SM, Aoki A, Noguchi K, Ishikawa I. Er:YAG laser irradiation increases prostaglandin E production via the induction of cyclooxygenase-2 mRNA in human gingival fibroblasts. J Periodontal Res 2005; $40(2)$ : $182-6$. [http://dx.doi.org/10.1111/j.1600-0765.2005.00789.x] [PMID: 15733154] 
[37] Ogita M, Tsuchida S, Aoki A, et al. Increased cell proliferation and differential protein expression induced by low-level Er:YAG laser irradiation in human gingival fibroblasts: proteomic analysis. Lasers Med Sci 2015; 30(7): 1855-66. [http://dx.doi.org/10.1007/s10103-014-1691-4] [PMID: 25429773]

[38] Hakki SS, Berk G, Dundar N, Saglam M, Berk N. Effects of root planing procedures with hand instrument or erbium, chromium:yttriumscandium-gallium-garnet laser irradiation on the root surfaces: a comparative scanning electron microscopy study. Lasers Med Sci 2010; 25(3): 345-53.

[http://dx.doi.org/10.1007/s10103-009-0643-x] [PMID: 19219484]

[39] Ting CC, Fukuda M, Watanabe T, Aoki T, Sanaoka A, Noguchi T. Effects of Er,Cr:YSGG laser irradiation on the root surface: morphologic analysis and efficiency of calculus removal. J Periodontol 2007; 78(11): 2156-64. [http://dx.doi.org/10.1902/jop.2007.070160] [PMID: 17970683]

[40] Hakki SS, Korkusuz P, Berk G, et al. Comparison of Er,Cr:YSGG laser and hand instrumentation on the attachment of periodontal ligament fibroblasts to periodontally diseased root surfaces: an in vitro study. J Periodontol 2010; 81(8): 1216-25.

[http://dx.doi.org/10.1902/jop.2010.090715] [PMID: 20476883]

[41] Kimura Y, Yu DG, Kinoshita J, et al. Effects of erbium, chromium:YSGG laser irradiation on root surface: morphological and atomic analytical studies. J Clin Laser Med Surg 2001; 19(2): 69-72. [http://dx.doi.org/10.1089/104454701750285386] [PMID: 11443792]

[42] Noori ZT, Fekrazad R, Eslami B, Etemadi A, Khosravi S, Mir M. Comparing the effects of root surface scaling with ultrasound instruments and Er,Cr:YSGG laser. Lasers Med Sci 2008; 23(3): 283-7. [http://dx.doi.org/10.1007/s10103-007-0480-8] [PMID: 17764026]

[43] de Oliveira GJ, Pavone C, Sampaio JE, Marcantonio RA. Influence of the angle of irradiation of the Er,Cr:YSGG laser on the morphology, attachment of blood components, roughness, and root wear: in vitro study. Lasers Surg Med 2010; 42(9): 683-91. [http://dx.doi.org/10.1002/lsm.20973] [PMID: 20976808]

[44] Lavu V, Sundaram S, Sabarish R, Rao SR. Root surface bio-modification with erbium lasers- A myth or a reality?? Open Dent J 2015; 9: 79-86. [http://dx.doi.org/10.2174/1874210601509010079] [PMID: 25713635]

[45] Cobb CM. Non-surgical pocket therapy: mechanical. Ann Periodontol 1996; 1(1): 443-90. [http://dx.doi.org/10.1902/annals.1996.1.1.443] [PMID: 9118268]

[46] Loos B, Nylund K, Claffey N, Egelberg J. Clinical effects of root debridement in molar and non-molar teeth. A 2-year follow-up. J Clin Periodontol 1989; 16(8): 498-504. [http://dx.doi.org/10.1111/j.1600-051X.1989.tb02326.x] [PMID: 2778083]

[47] Gupta M, Lamba AK, Verma M, et al. Comparison of periodontal open flap debridement versus closed debridement with Er,Cr:YSGG laser. Aust Dent J 2013; 58(1): 41-9.

[http://dx.doi.org/10.1111/adj.12021] [PMID: 23441791]

[48] Cortellini P, Tonetti MS. Clinical and radiographic outcomes of the modified minimally invasive surgical technique with and without regenerative materials: a randomized-controlled trial in intra-bony defects. J Clin Periodontol 2011; 38(4): $365-73$. [http://dx.doi.org/10.1111/j.1600-051X.2011.01705.x] [PMID: 21303402]

[49] Kao RT, Nares S. Periodontal regeneration-Intrabony defects: A systematic review. AAP Regenerat Workshop 2015; S77-104.

(C) Al-Falaki et al. ; Licensee Bentham Open.

This is an open access article licensed under the terms of the Creative Commons Attribution-Non-Commercial 4.0 International Public License (CC BY-NC 4.0) (https://creativecommons.org/licenses/by-nc/4.0/legalcode), which permits unrestricted, non-commercial use, distribution and reproduction in any medium, provided the work is properly cited. 